Session 1426

\title{
Portable Experimental Apparatus for Demonstrating Thermodynamics Principles
}

\author{
Hosni I. Abu-Mulaweh \\ Department of Engineering \\ Indiana University-Purdue University at Fort Wayne \\ Fort Wayne, IN 46805, USA
}

\begin{abstract}
A refrigeration system experimental apparatus was designed, developed and constructed for the undergraduate mechanical engineering laboratory at Indiana University-Purdue University at Fort Wayne. The purpose of the experimental apparatus is to demonstrate thermodynamics processes and systems which are fundamental to understanding the basic concepts of thermodynamics, such as the first and second laws of thermodynamics. In addition, this apparatus demonstrates a vapor compression refrigeration cycle. This paper will present a set of thermodynamics experiments in which the first and second law of thermodynamics are employed to determine the heat gained by the refrigerant in the evaporator, the heat rejected from the refrigerant in the condenser, and the isentropic efficiency of the compressor. The objective of these experiments is to assist the undergraduate mechanical engineering students in understanding the basic thermodynamics processes by utilizing real life applications. This project was completed with the assistance of an Undergraduate Senior Project Grant from the American Society of Heating, Refrigeration, and Air Conditioning Engineers (ASHRAE).
\end{abstract}

\section{Introduction}

Thermodynamics is a basic and very important topic that deals with energy and has long been an essential part of mechanical engineering curricula all over the world. The principles of thermodynamics are based on people's everyday experiences and observations. However, the majority of students perceive thermodynamics as a difficult subject. Mechanical engineers use thermodynamics principles as part of an engineering science to study and design a wide variety of energy systems, such as jet engines and rockets, refrigeration systems, air conditioning systems, chemical processes, and power plants.

Because of these facts, it was decided that an experimental apparatus designed to demonstrate the thermodynamics processes and systems is needed. Such an apparatus would enhance and add another dimension to the teaching/learning process of the subject of thermodynamics. The students would be able to apply thermodynamics principles such as the first and second laws and 
others that they learned in the classroom lectures to real life application. This approach could make the subject of thermodynamics a more pleasant experience for the undergraduate mechanical engineering students.

Indiana University-Purdue University, Fort Wayne is a state supported institution. Thus makes the purchase of new instructional laboratory apparatus a challenge due to typical budgetary limitations. In addition, the apparatus designed by companies specializing in education equipment may not exactly reflect the educational objective intended by the faculty. These obstacles had forced us to seek and search different venues to acquire a portable experimental laboratory apparatus for demonstrating thermodynamics processes and principles. We concluded that such an apparatus can be designed, developed and constructed "in house" within a manageable budget. This can be successfully accomplished by taking advantage of the capstone senior design project and ASHRAE Undergraduate Senior Project Grant Program. The purpose of this ASHRAE's program is to fund equipment for undergraduate engineering senior projects on ASHRAE-related topics. Obtaining these types of grants to support the design, development and construction of instructional laboratory apparatus would greatly help the normally stressed department's equipment budget. In addition, it would provide the students with quality and real life design projects to work on.

The task to design, develop and construct an instructional laboratory apparatus to demonstrate thermodynamics processes and principles began with an application to the ASHRAE Undergraduate Senior Project Program. The proposal was to design a refrigeration system for a small compartment. Subsequent to the awarding of the project grant in the amount of $\$ 1775$ from ASHRAE, a student senior design group was selected to work on the project.

\section{The Design Process}

The design process that the students follow in the capstone senior design projects is the one outlined by Bejan et al. [1] and Jaluria [2]. The first essential and basic feature of this process is the formulation of the problem statement. The formulation of the design problem statement involves determining the requirements of the system, the given parameters, the design variables, any limitations or constraints, and any additional considerations arising from safety, financial, environmental, or other concerns. The following is a summary of these guidelines:

- The system will be based on the vapor-compression refrigeration cycle.

- All components of the system must be visible and the different states must be instrumented with thermocouples to measure the temperature and pressure gages to measure the pressure. This is essential because, as mentioned above, the finished product would serve as an instructional laboratory apparatus for demonstrating thermodynamics processes and principles.

- The inside dimensions of the compartment should be $38 \mathrm{~cm}$ by $38 \mathrm{~cm}$ by $50 \mathrm{~cm}$ with a

Proceedings of the 2002 American Society for Engineering Education Annual Conference \& Exposition Copyright (C) 2002, American Society for Engineering Education 
square base.

- The system should keep the refrigerated compartment at approximately $-5^{\circ} \mathrm{C} \pm 2^{\circ} \mathrm{C}$.

- The working fluid for the system (i.e., the refrigerant) must be environmentally friendly.

- The system should operate on regular 110 volt, single phase, grounded, $60 \mathrm{~Hz}$ AC power from a standard outlet.

- The system should be rigid and stable and not likely to tip over accidentally.

- The cost of the system should not exceed $\$ 1775$.

After the problem statement was formulated, several conceptual designs were considered and evaluated. Each design concept was evaluated by the following criteria: Effectiveness as an instructional laboratory apparatus, Cost, Safety, Simplicity, and Size.

The final design was chosen to be a Rotary Screw Compressor Single Stage Vapor Compression Refrigeration Cycle. The refrigerant that was selected as working fluid is R-134a. This refrigerant is considered to be safe to the environment. Details of the vapor-compression refrigeration cycle can be found in any Fundamentals of Thermodynamics textbook such as Sonntag et al. [3] and a schematic of this cycle is shown in Figure 1. The compressor is used to compress (raise the pressure of) the refrigerant from a saturated vapor to a superheated vapor (41). The superheated vapor is then channeled into the condenser where heat is removed from the fluid to the surroundings causing the working fluid to revert from a superheated vapor to a saturated liquid (1-2). The saturated liquid then enters the expansion valve where it undergoes an expansion process (2-3). This lowers the temperature of the fluid to the desired temperature for the evaporator. At this point, the refrigerant is in the saturated region. The evaporator is used to remove heat from the compartment of the system to the working fluid, which will change to a saturated vapor and is then returned to the compressor (3-4).

\section{Equipment Description}

The refrigeration system instructional laboratory apparatus that was designed and constructed is shown schematically in Figure 2. The working fluid (R-134a) temperature and pressure can be measured at the four different states indicated in Figure1. In addition, the mass flow rate of the refrigerant can be measured using a flow meter. The measurements of the temperature and pressure at the above mentioned states allow the determination of the various thermodynamics properties needed for the demonstrating the thermodynamics principles, such as the first and second laws of thermodynamics. 


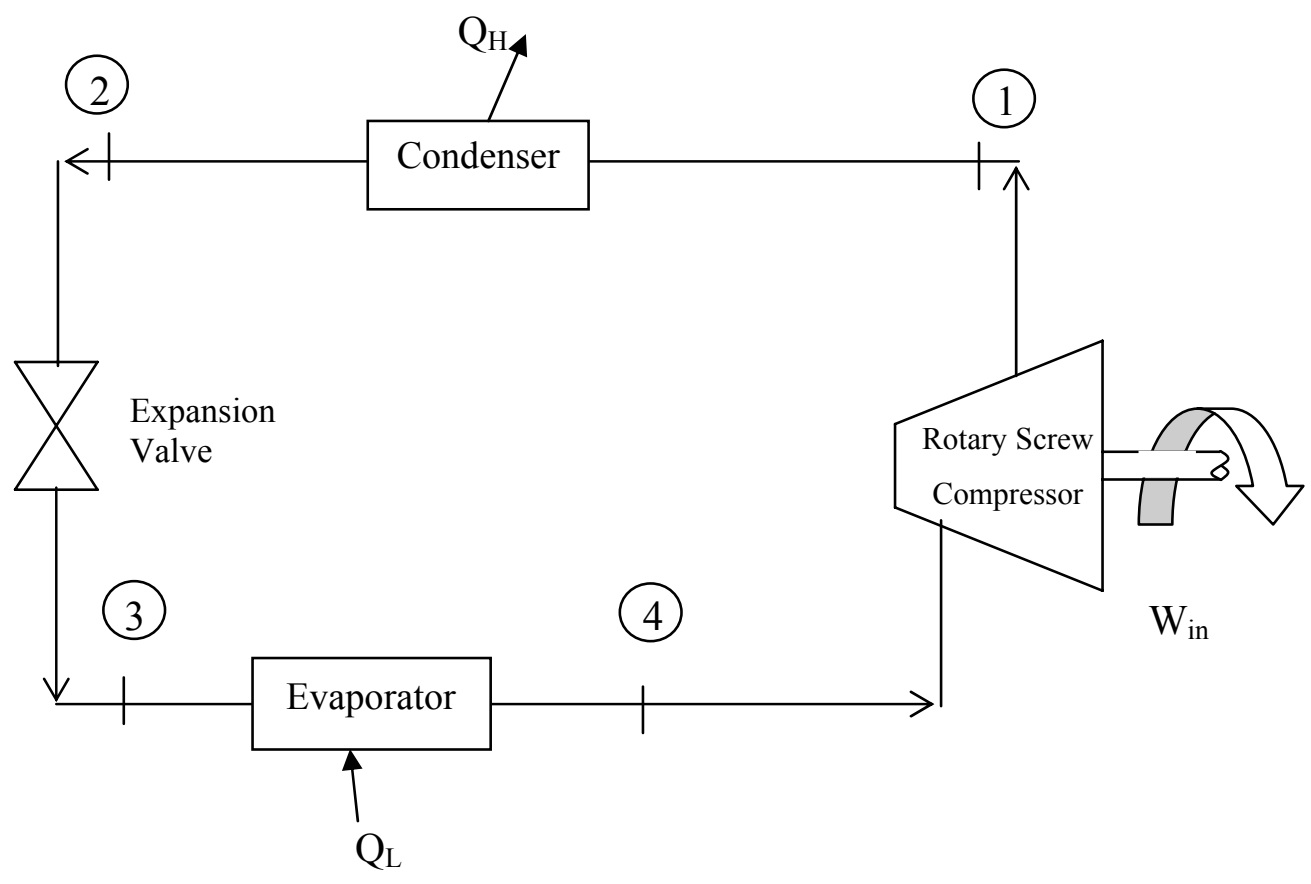

Figure 1: A schematic of the Rotary Screw Driven Vapor Compression Cycle.

All the components are located on a bench top. This kind of arrangement makes the apparatus portable and easy to move from one location to another using a cart. The bench top is made of a $3 / 4$ " melamine shelving which was purchased precut to $24 " \mathrm{x} 48$ ". The compressor chosen is a rotary screw type that has a capacity of $470 \mathrm{Btu} / \mathrm{hr}$. It was purchased from Copeland. Both the condenser and the evaporator coils were constructed by HeatCraft Inc. according to the design parameters. The evaporator is installed next to the ceiling inside the refrigerated compartment. Two holes were drilled through the back of the compartment to allow the evaporator lines to pass through. After the evaporator was installed in the compartment, and the lines were connected to the thermal expansion valve and the compressor, the drilled holes were filled with spay-in insulation. The condenser is installed outside the compartment and is been supported on the bench top by using a wooden frame. A fan assembly is installed behind the condenser to enhance the heat loss from the condenser.

The walls of the compartment consist of three layers. A formed 20 gauge sheet metal interior, a $3 / 4$ " thick "blue Board" (extruded R-4 insulating board) liner, and a formed 20 gauge metal exterior. Assembly of the compartment began by having the individual sheet metal components professionally fabricated. The exterior of the compartment was the first to be assembled. With the bottom and three sides screwed together, pieces of the insulating blue board were custom cut to fit. After placing the blue board, all three of the interior panels were installed. Each panel was 


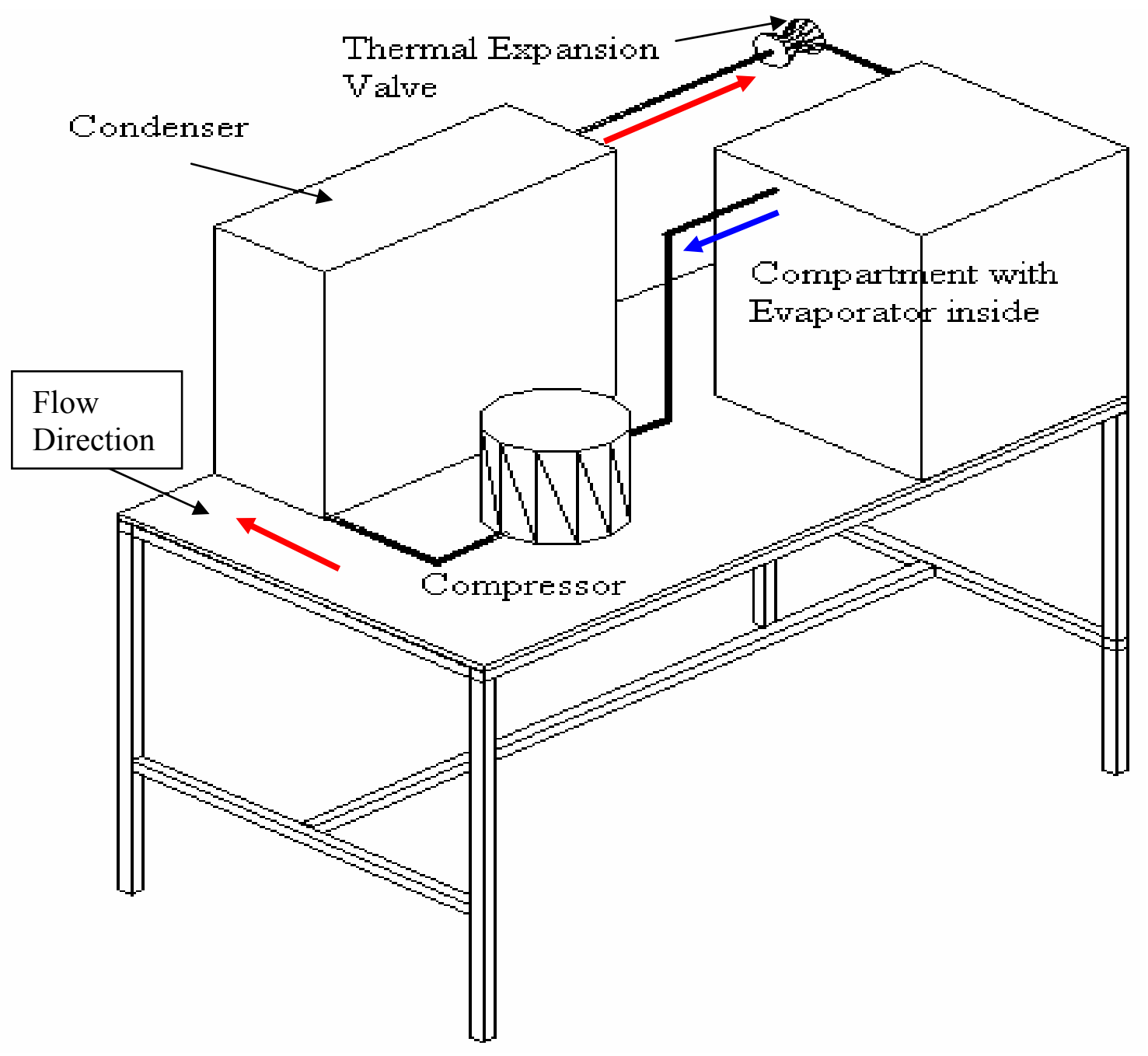

Figure 2: Schematic of the overall refrigeration system apparatus 
screwed to the adjacent panels using self-tapping sheet metal screws. The top was the final panel attached to the main compartment.

The choice of the thermal expansion valve (TXV) was base on the following requirements: adequate capacity, be able to provide the required pressure drop, be able to tolerate the refrigerant, and be able to operate within the temperature range. The model chosen is from Alco Products. Its inlet and exit line sizes are somewhat larger than the lines that are being used, so suitable couplings were needed to be placed at each point to adapt the line sizes. In addition to the inlet and outlet lines, there are two other connections to be made with the chosen expansion valve. One connection is from the pressure tap on the valve to the exit line of the evaporator. This connection serves to monitor the pressure of the line connecting the evaporator and the compressor. The other connection ( $5 \mathrm{ft}$ long) leads to the remote sensing bulb, which does not even contact the refrigerant. Its function is to monitor the temperature of the tube on the compressor side of the evaporator. It accomplishes this by measuring the pressure of a working fluid inside the bulb as it changes with the temperature of the line to which it is connected. The purpose of this type thermal expansion device is to monitor the state of the refrigerant entering the compressor and to maintain a given level of superheating in order to avoid compressor damage. In addition, a filter dryer was installed directly after the TXV to dry the refrigerant that leaves the thermal expansion valve by removing any water vapor that entered the system during assembly.

The tubing that was used in this experimental apparatus is of type L, 3/16" OD copper tube. It is rated a maximum of $300 \mathrm{psi}$ at $180^{\circ} \mathrm{F}$. The maximum pressure at any point in the system is 112 psi. This gives a safety factor of 2.68 for the tube. All joint were brazed. It should be noted that the tube was sized as recommended by the ASHRAE guidelines for line sizing. After all the components were assembled, the copper lines were checked for leaks and then the system was charged using refrigerant R-134a and an oil charge of $2 \mathrm{oz}$. In addition, the copper lines were insulated and wrapped with either red or blue duct tape, indicating hot line or cold line, respectively.

The control system consists of an on/off switch from Ranco actuated by a temperature-sensing bulb, to regulate the temperature inside the compartment. Since the operating point is $-5^{\circ} \mathrm{C}$, the control system will turn the motor on at $-4^{\circ} \mathrm{C}$ and off at $-6^{\circ} \mathrm{C}$. The thermo expansion valve is also considered a part of the control system; as it will maintain and control the amount of superheat exiting the evaporator. This device was installed to the side of the compartment using several brackets. This device controls the compressor by utilizing a sensing bulb placed inside the compartment to read the internal compartment temperature. A type $\mathrm{T}$ thermocouple was also placed inside the compartment to read the internal temperature. The sensing bulb and the thermocouple were placed on the inside of the compartment, through a hole drilled in the side of the compartment. Once the sensing bulb and the thermocouple were placed inside the compartment the hole was spray-foamed to help seal the compartment. 


\section{Testing Procedure and Sample Results}

The locations at which the temperature and pressure of the refrigerant are to be measured are summarized below and illustrated in Figure 3. In addition, a thermocouple is used to monitor the temperature inside the compartment.

- Gauge and Thermocouple \#1-Condenser inlet / Compressor outlet

- Gauge and Thermocouple \#2-Condenser outlet / Thermal Expansion Valve inlet

- Gauge and Thermocouple \#3-Thermal Expansion Valve outlet / Flow meter inlet

- Gauge and Thermocouple \#4-Flow meter outlet / Evaporator inlet

- Gauge and Thermocouple \#5-Evaporator outlet / Compressor inlet

- Thermocouple only \#6-Compartment Interior

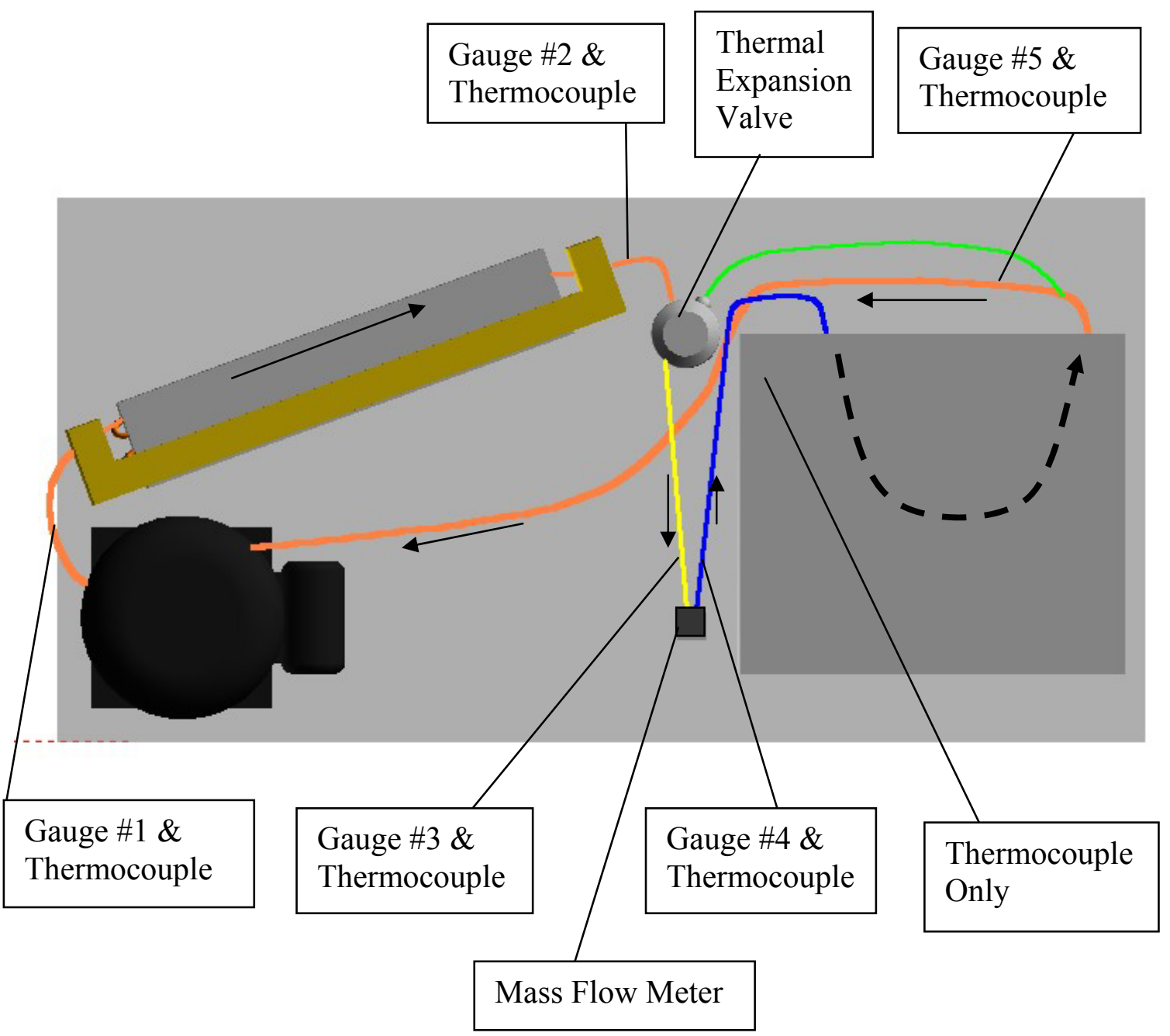

Figure 3: Pressure gauges and thermocouples placement 
The setting of the thermal expansion valve (i.e., the pressure drop across the thermal expansion valve) greatly affects the performance. The TXV is a purely mechanical, closed-loop, control device. It adjusts the amount of pressure drop between the high and low-pressure sides of the system based on pressure and temperature inputs from the evaporator exit. The reaction time of this device manifests itself in the sinusoidal nature of the pressure and temperature variations. This phenomenon is known as hunting. In an unstable system, the hunting is severe and can lead to inefficiency and premature component failure. Small and relatively uniform oscillations are indicative of a stable, appropriately sized system. The pressure drop across the thermal expansion valve can be adjusted by turning a small screw located on the bottom of it. Several runs were carried out to find a suitable setting for the thermal expansion valve.

The measured data is collected utilizing a data acquisition system. This approach allows the students to observe the transient performance of the system. Table 1 shows a sample data that was obtained. This data represents the final measurements taken before the compressor kicked off by the control system as a result of the temperature inside the compartment reaching the operating point.

Table 1: Measured data

\begin{tabular}{|c|c|c|}
\hline $\begin{array}{c}\text { Gauge } \\
\text { Location }\end{array}$ & $\begin{array}{c}\text { Temperature } \\
\left({ }^{\circ} \mathrm{F}\right)\end{array}$ & $\begin{array}{c}\text { Pressur } \\
\mathrm{e} \\
(\mathrm{psi})\end{array}$ \\
\hline 1 & 127.7 & 99.7 \\
\hline 2 & 67.71 & 99.7 \\
\hline 3 & 1.13 & 22.6 \\
\hline 4 & -5.12 & 21.8 \\
\hline 5 & 18.73 & 17.7 \\
\hline Compartment & 19.58 & \multicolumn{1}{|l}{} \\
\hline Flow Rate & $0.0054 \mathrm{lbm} / \mathrm{s}$ & \multicolumn{1}{|l}{} \\
\hline
\end{tabular}

From the measured data, several quantities of interest can be determined using the first law and the second law of thermodynamics. These quantities include the heat transfer into the evaporator, $\mathrm{Q}_{\text {in, }}$, the heat rejected from the condenser, $\mathrm{Q}_{\text {out, }}$, the work required, $\mathrm{W}_{\text {in }}$, (the input work to the compressor), the isentropic efficiency of the compressor, Eff. and the coefficient of performance, COP, of the refrigeration system. The summary of these results is shown in Table 2.

Table 2:

\begin{tabular}{|c|c|c|c|c|}
\hline $\mathrm{Q}_{\text {in }}(\mathrm{Btu} / \mathrm{hr})$ & $\mathrm{Q}_{\text {out }}(\mathrm{Btu} / \mathrm{hr})$ & $\mathrm{W}_{\text {in }}(\mathrm{Btu} / \mathrm{hr})$ & Eff. (\%) & COP \\
\hline 1422.1 & 1782.5 & 360.4 & 89.2 & 3.95 \\
\hline
\end{tabular}


Figure 4 illustrates the T-s diagram with the vapor dome of the actual vapor-compression refrigeration cycle for the current system. This cycle is based on the data shown in Table 1. As can be seen from the figure, the actual cycle is somewhat different from the familiar ideal refrigeration cycle (see Sonntag et al. [3], page 398). This is due to heat gain through exposed tubes, pressure losses in lines and fittings, a pressure drop through the orifice in the flow meter. In addition, there is a slight amount of superheat between the evaporator output and the compressor inlet, in order to insure that no liquid slugs enter the compressor. This additional superheat is a built in safety factor, and is regulated by the thermal expansion valve.

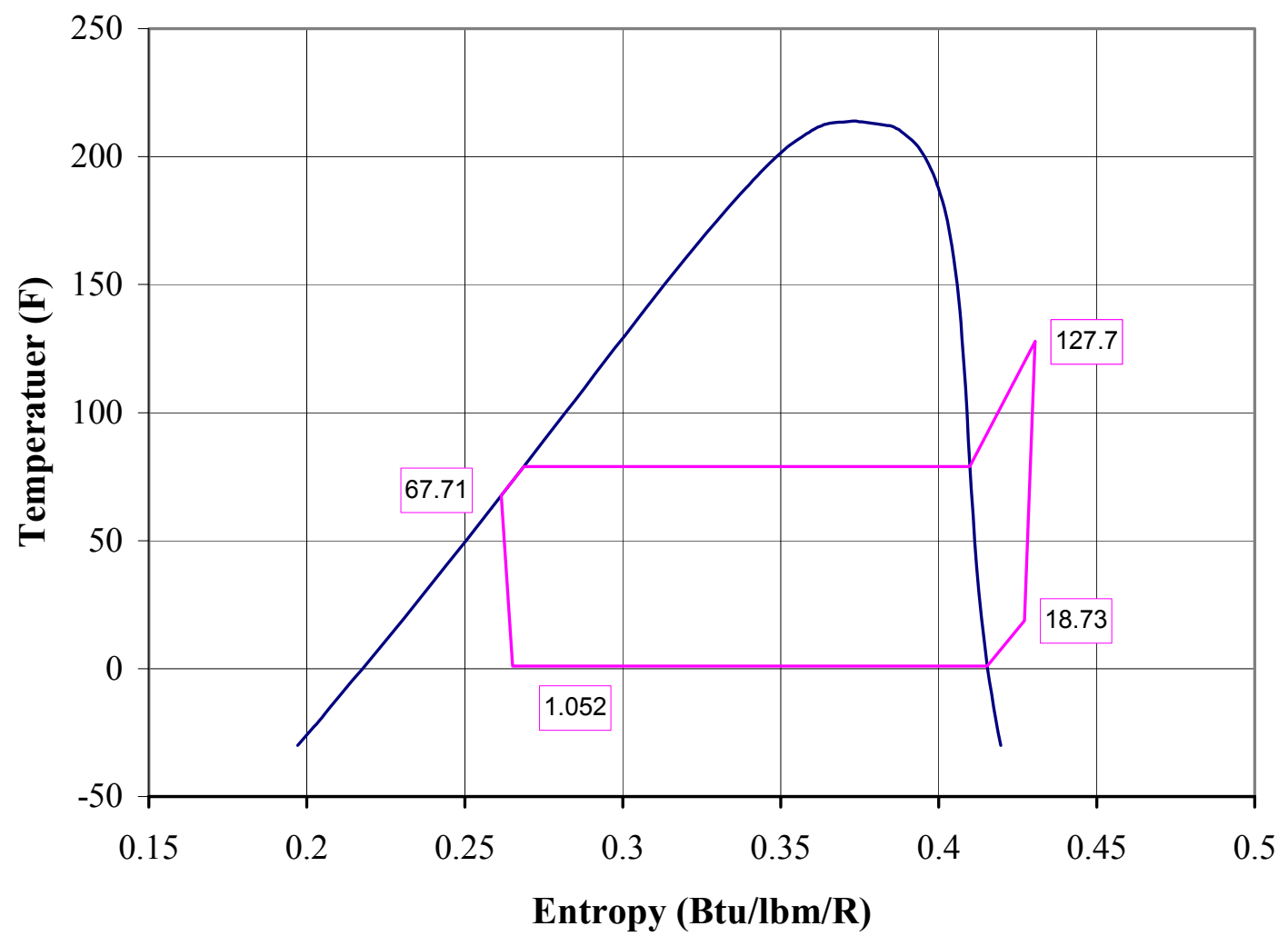

Figure 4: The actual vapor-compression refrigeration cycle. 


\section{Conclusion}

The experimental apparatus described in this paper is a valuable addition to the undergraduate mechanical engineering laboratory. This was accomplished with zero cost to the engineering department at IPFW. This was made possible for two main reasons: the financial support from ASHRAE and the effort of a capstone senior design team. The experimental apparatus is portable. This allows the system to be used for laboratory experiments and classroom demonstrations. The sample results prove that the apparatus is well designed for its intended purpose of demonstrating basic thermodynamics processes and principles.

\section{Acknowledgement}

This project was completed with the assistance of an Undergraduate Senior Project Grant from ASHRAE. The members of the capstone senior design team are Steven Juricak and Andrew Magner.

\section{Bibliography}

1. Bejan, A., Tsatsaronis, G., and Moran, M. (1996), “Thermal Design \& Optimization," John Wiley \& Sons, Inc., New York.

2. Yogesh Jaluria (1998), "Design and Optimization of Thermal Systems," McGraw-Hill, New York.

3. Sonntag, R. E., Borgnakke, C., and Van Wylen, G. J. (1998), "Fundamentals of Thermodynamics," $5^{\text {th }}$ Edition, John Wiley \& Sons, Inc., New York.

\section{HOSNI I. ABU-MULAWEH}

Hosni I. Abu-Mulaweh is an Assistant Professor of Mechanical Engineering at Indiana University-Purdue University, Fort Wayne, Indiana. He earned his B.S., M.S., and Ph.D. in Mechanical Engineering from the University of Missouri-Rolla, Rolla, Missouri. His areas of interest are Heat Transfer, Thermodynamics, and Fluid Mechanics. 